[0212-7199 (2006) 23: 12; pp 585-587] ANALES DE MEDICINA INTERNA Copyright @ 2006 ARAN EDICIONES, S.L.

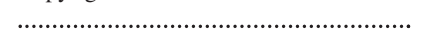

AN. MED. INTERNA (Madrid) Vol. 23, N. ${ }^{\circ} 12$, pp. 585-587, 2006

\title{
Tratamiento paliativo del cáncer de cabeza de páncreas, dos años antes del diagnóstico
}

\author{
M. A. ANÍA LAHUERTA, J. VILLALTA CABERO' \\ Servicio de Medicina Interna, ${ }^{I}$ Servicio de Cirugía General y Aparato Digestivo. Hospital \\ de Barbastro. Huesca
}

\begin{abstract}
RESUMEN
El cáncer de páncreas es una neoplasia agresiva, con mal pronóstico y poca supervivencia. La mayoría de los pacientes se diagnostican en fases avanzadas, por lo que sólo se puede realizar tratamiento paliativo. La pancreatitis crónica predispone al desarrollo de cáncer de páncreas, considerándose que la inflamación juega un papel importante en el desarrollo temprano de la malignidad, estableciéndose un nexo de unión entre ambas patologías. El diagnóstico diferencial entre la pancreatitis crónica y el cáncer de páncreas en las fases iniciales es difícil de realizar por la escasa sensibilidad y especificidad de las pruebas diagnósticas de imagen y de los marcadores tumorales. Presentamos un caso clínico sugestivo de cáncer de páncreas, cuyo diagnóstico se realizó dos años después del tratamiento paliativo.
\end{abstract}

PALABRAS CLAVE: Cáncer de páncreas. Pancreatitis crónica. Tratamiento paliativo.

\author{
PANCREATIC CANCER THAT WAS DIAGNOSED TWO YEARS \\ AFTER PALLIATIVE TREATMENT
}

\begin{abstract}
Pancreatic cancer is an aggressive neoplasm, with poor prognosis and survival. As most patients with pancreatic cancer are diagnosed at an advanced stage, the objetive of mostly treatment is palliative. Predisposing medical conditions for the development of pancreatic cancer include chronic pancreatitis. The link between the two pathologies is supported in that pancreatic inflammation may play a role in the early development of pancreatic malignancy. The difficulties in discriminating between chronic pancreatitis and adenocarcinoma in the early state, using currently employed diagnosis imaging and tumour marker analysis, result in poor sensitivity and specificity in the diagnosis. We report one case suggestive of pancreatic cancer that was diagnosed two years after palliative treatment.
\end{abstract}

KEY WORDS: Pancreatic cancer. Chronic pancreatitis. Palliative treatment.

Anía Lahuerta MA, Villalta Cabero J. Tratamiento paliativo del cáncer de cabeza de páncreas, dos años antes del diagnóstico. An Med Interna (Madrid) 2006; 23: 585-587.

\section{INTRODUCCIÓN}

El cáncer de páncreas es uno de los tumores de peor pronóstico, con supervivencia al cabo de cinco años del 1 al $4 \%$ (1). Un diagnóstico precoz puede beneficiarse de un tratamiento curativo, sin embargo, la mayoría de los pacientes presentan enfermedad diseminada en el momento del diagnóstico, sólo subsidiario de tratamiento paliativo con prótesis endoluminales. El 90\% corresponden a adenocarcinomas ductales, que se localizan entre un $60-70 \%$ en la cabeza del páncreas. El diagnóstico del cáncer de páncreas es en ocasiones difícil de realizar, presentando inicialmente síntomas inespecíficos, similares a otras entidades como la pancreatitis crónica.

La pancreatitis crónica es uno de los factores de riesgo implicados en el desarrollo del cáncer de páncreas (2). Presentamos este caso clínico como ejemplo de la dificultad para diferenciar ambas patologías en estadios iniciales, diagnosticándose y tratándose paliativamente una pancreatitis crónica como un cáncer de páncreas avanzado, dos años antes de la confirmación histológica.

\section{CASO APORTADO}

Varón de 74 años, sin alergias conocidas y con antecedentes patológicos de fractura de fémur izquierdo tras accidente hacía 40 años, con osteomielitis fistulizada a través de la piel a ese nivel en el año 2002, hipertrofia benigna de próstata y diabetes mellitus tipo 2. No fumador, no ingestión habitual de bebidas alcohólicas. Trata-

Trabajo aceptado: 12 de junio de 2006

Correspondencia: Ma Aldonza Anía Lahuerta. Servicio de Medicina Interna. Hospital de Barbastro. Ctra. N-240, s/n. 22300 Barbastro (Huesca). e-mail: aania@salud.aragon.es 
miento habitual con repaglinida y terazosina. Ingresa en el Servicio de Medicina Interna en marzo del 2003 por ictericia indolora con prurito generalizado, refiriendo pérdida de peso progresiva, sin dolor abdominal. A la exploración física destacaba ictericia franca y delgadez; se palpaba una vesícula distendida no dolorosa. Resto de la exploración sin interés. Analíticamente se confirma colestasis con bilirrubina total $23,7 \mathrm{mg} / \mathrm{dl}$, bilirrubina directa $19,7 \mathrm{mg} / \mathrm{dl}$, aumento de fosfatasa alcalina y GGT. Los marcadores tumorales, alfafetoproteina, CEA y CA 19,9 dentro de la normalidad. La ecografía abdominal mostraba distensión de vesícula biliar sin signos inflamatorios ni colelitiasis, con dilatación de vía biliar intra y extrahepática, ecoestructura hepática sin lesiones focales y con área pancreática mal visualizada. La TAC abdominal, muestra las mismas anomalías en vesícula y vía biliar, con cabeza pancreática de tamaño normal, sin lesiones focales hepáticas ni adenopatías retroperitoneales. Se realiza CPRE (Fig. 1), cuyo informe describe una papila de aspecto normal, estenosis de Wirsung y colédoco a la altura de la cabeza del páncreas, realizandose esfinterotomía e implantándose prótesis plástica biliar. Diagnóstico colangiográfico: colestasis por neoplasia de cabeza de páncreas. No se realizó biopsia ni cepillado. Tras el drenaje biliar la ictericia disminuye progresivamente, solicitando la familia del paciente el traslado a otro centro hospitalario más cercano a su residencia habitual.

En abril de 2004, un año después, el paciente acude a nuestra consulta de Digestivo, remitido desde Atención Primaria, por presentar síndrome diarréico con abundante borborigmo y dispepsia digestiva. Refiere que en el centro hospitalario al que se trasladó, se reali-

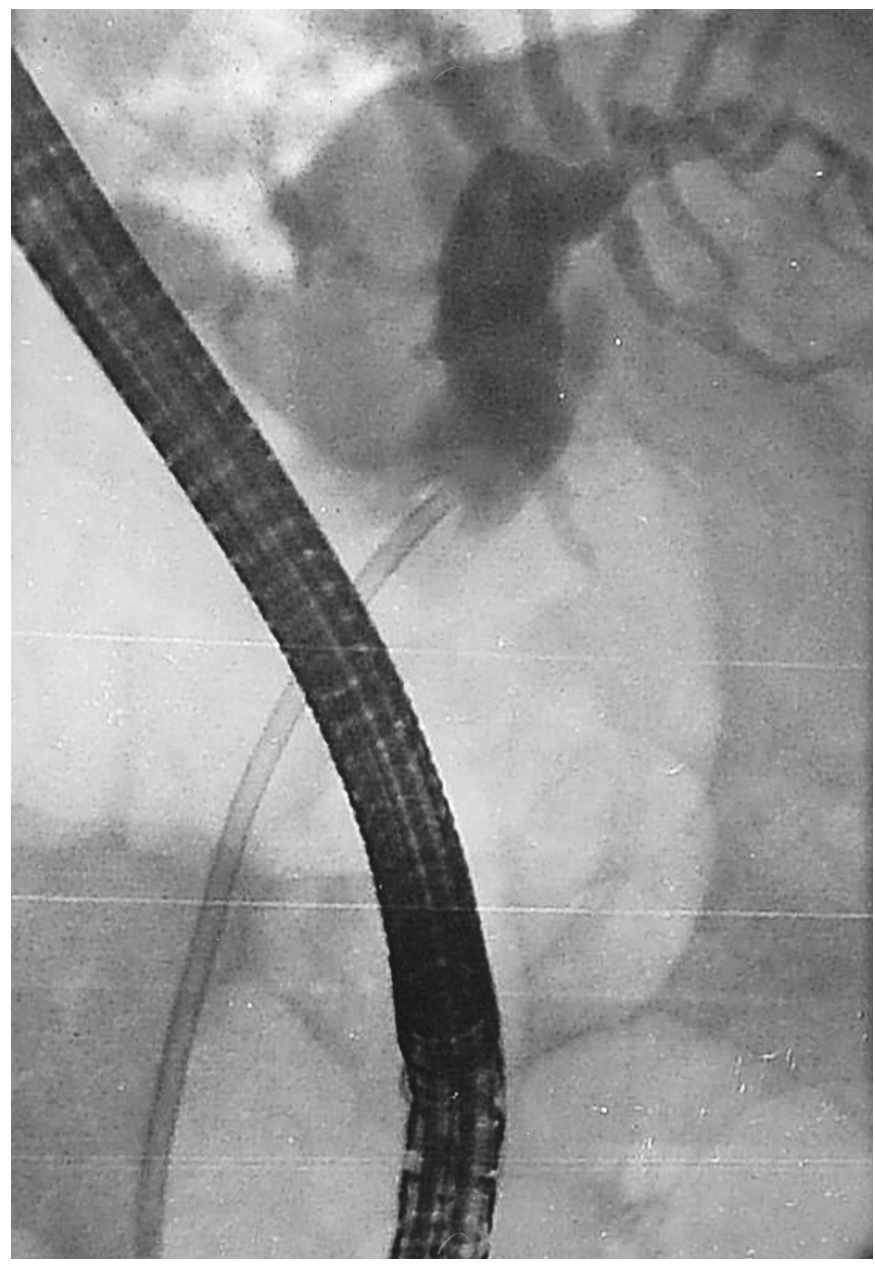

Fig. 1. Colangiopancreatografía retrógrada endoscópica (CPRE). Estenosis de Wirsung y colédoco a la altura de la cabeza del páncreas con dilatación supraestenótica. Se implanta prótesis plástica con correcto drenaje biliar. zó cambio de prótesis biliar a los 10 días del ingreso por obstrucción con empeoramiento de la ictericia, colocándose prótesis metálica expandible. Se solicitó colonoscopia, hallándose en colon ascendente adenocarcinoma bien diferenciado sin extensión tumoral. En junio de 2004, laparotomía con hemicolectomía derecha con anastómosis mecánica término-lateral y biopsia hepática, observándose en el acto quirúrgico un páncreas con manchas de esteatonecrosis de la cabeza a la cola, sugestivo de pancreatitis crónica. No se actua sobre el tracto biliar. La biopsia hepática presentaba cambios inflamatorios portales con leve fibrosis y colestasis leve. Se establece el diagnóstico quirúrgico de pancreatitis crónica, sin hallarse tumoración pancreática, al menos macroscopicamente. Durante el seguimiento se realizaron TAC abdominales postquirúrgicos, destacando en noviembre de 2004, ligera disminución de la densidad habitual de la región cefálica pancreática, con cuerpo y cola de aspecto atrófico, dilatación del Wirsung, prótesis biliar metálica bilioduodenal, sin otras alteraciones. El CA.19,9 se mantiene dentro de valores normales.

En febrero de 2005, el paciente ingresa de nuevo por ictericia franca, intolerancia digestiva, diarrea y afectación del estado general. En la TAC abdominal se evidencia severa dilatación de la vía biliar intra y extrahepática con distensión de vesícula biliar, probablemente en relación con dificultad de drenaje de la prótesis biliar. La cabeza pancreática presentaba límites mal definidos con aspecto global hipodenso. El paciente es reintervenido por ictericia obstructiva severa, practicándose coledocoyeyunostomía latero-lateral y colecistectomía, obteniéndose citología por punción de cabeza de páncreas que confirma el diagnóstico de adenocarcinoma con diferenciación mucinosa. Después de un postoperatorio complicado con ileo paralítico prolongado y evisceración que requirió reintervención quirúrgica, el paciente evoluciona hacia insuficiencia hepática grave falleciendo, a los pocos días, dos años después del ingreso inicial en nuestro hospital.

\section{DISCUSIÓN}

La supervivencia del cáncer de páncreas, depende del estado general del paciente y de la extensión de la enfermedad en el momento del diagnóstico. Una de sus características es la invasión precoz de ganglios linfáticos e hígado. La mayoría de los casos se presentan en edades superiores a 50 años, siendo más frecuente en varones. El $90 \%$ son adenocarcinomas que crecen a partir de los ductos pancreáticos, y se localizan en la cabeza pancreática. Entre los factores etiológicos implicados destaca el consumo de cigarrillos, café y alcohol, síndromes hereditarios, cambios genéticos del ADN, y pacientes gastrectomizados, así como, diabetes mellitus y pancreatitis crónica (3). Respecto a esta última, se conoce el riesgo de padecer adenocarcinoma de páncreas en la pancreatitis crónica $(4,2)$, pero se desconoce la causa de esa asociación, a pesar de presentar, ambas patologías, mutaciones específicas de determinados genes y marcadores comunes $(5,6)$. Las manifestaciones clínicas del cáncer de páncreas son inespecíficas, variando desde el dolor abdominal, la ictericia, pérdida de peso, diabetes a la dispepsia digestiva. El tratamiento con intención curativa es la resección quirúrgica, en pacientes con enfermedad localizada. En el cancer de páncreas diseminado, o localmente avanzado, se indica tratamiento paliativo de sus complicaciones biliares o gástricas, siendo pobres los resultados de la quimioterapia. Uno de los tratamientos paliativos más utilizado es la prótesis biliar, en caso de ictericia obstructiva, existiendo varios tipos, entre ellas las dos referidas en el caso clínico, plástica y metálica autoexpandible.

La pancreatitis crónica se caracteriza por una pérdida progresiva del parénquima pancreático, con deterioro de sus fun- 
ciones exocrinas y endocrinas (7). Entre los factores implicados en su patogénesis se encuentran factores genéticos, como la pancreatitis hereditaria y la pancreatitis autoinmune, factores dietéticos, idiopáticos, cálculos biliares, y con mayor frecuencia la ingesta excesiva de alcohol. Muchos pacientes presentan una clínica silente, y otros presentan síntomas inespecíficos, como los referidos en el cáncer de páncreas, dolor abdominal, ictericia, pérdida de peso, diabetes, esteatorrea e intolerancia digestiva entre otros.

El diagnóstico diferencial entre cáncer de páncreas y pancreatitis crónica puede ser difícil de realizar, no sólo por las manifestaciones clínicas inespecíficas, sino también porque en ocasiones las técnicas de imagen utilizadas para el diagnóstico no son concluyentes en fases iniciales de la enfermedad. Se investigan mutaciones genéticas que sirvan para un diagnostico diferencial temprano, habiéndose identificado genes comunes en tejidos de ambas patologías $(8,9)$.

El caso clínico que exponemos, es el de un varón con sospecha clínica de cáncer de páncreas, que presenta imágenes de estenosis por compresión extrínseca del colédoco distal, sin toma de biopsia ni citología, sugestivo de cáncer de páncreas y que se trata con método paliativo.

Es llamativa la evolución tan lenta para una patología neoplásica que se consideraba en fase avanzada por la clínica y el tratamiento paliativo instaurado. La observación global "a posteriori" nos plantea dos hipótesis: la existencia inicial de un adenocarcinoma pancreático sospechado pero no evidenciado, o la transformación maligna de una pancreatitis crónica, supuestamente favorecida por el implante de prótesis biliares. Podemos interpretar la secuencia clínica partiendo de una inflamación crónica que induce cambios celulares (10), con aumento del recambio celular, y alteraciones en el genoma (11), bajo un estímulo continuo de prótesis biliar metálica infección local, favoreciendo la transformación neoplásica.

El diagnóstico final es de adenocarcinoma de cabeza de páncreas, tras un proceso de pancreatitis crónica tratada con prótesis biliar durante dos años.

\section{Bibliografía}

1. Parker SL, Tong T, Bolden S, Wingo PA. Cancer statistics. CA Cancer J Clin 1997; 1997: 47: 5-27.

2. Talamini G, Falconi M, Bassi C, Sartori N, Salvia R, Caldiron E, et al. Incidence of cancer in the course of chronic pancreatitis. Am J Gastroenterol 1999; 94: 1253-60.

3. Ghadirian P, Lynch HT, Krewski D. Epidemiology of pancreatic cancer: An overview. Cancer Detect Prev 2003; 27: 87-93.

4. Malka D, Hammel P, Maire F, Rufat P, Madeira I, Pessione F, et al. Risk of pancreatic adenocarcinoma in chronic pancreatitis. Gut 2002; 51: 849-52.

5. Maire F, Micard S, Hammel P, Voitot H, Lévy P, Cugnenc PH, et al. Differential diagnosis between chronic pancreatitis and pancreatic cancer: Value of the detection of KRAS2 mutations in circulating DNA. Br J Cancer 2002; 87: 551-4.

6. Slesak B, Harlozinska-Szmyrka A, Knast W, Sedlaczek P, van Dalen A, et al.Tissue polypeptide specific antigen (TPS), a market for differentiation between pancreatic carcinoma and chronic pancreatitis. A compa- rative study with CA 19.9. Cancer 2000; 89: 83-8.

7. Kloppel G, Maillet B. The morphological basis for the evolution of acute pancreatitis into chronic pancreatitis. Virchows Arch A Pathol Anat Histopathol 1992; 420: 1-4.

8. Ebert M, Schandl L, Schmid RM. Differentiation of chronic pancreatitis from pancreatic cancer: Recent advances in molecular diagnosis. Dig Diseases 2001; 19: 32-6.

9. Binkley MJ, Zhang L, Greenson JK, Giordano TJ, Kuick R, Misek D, et al. The molecular basis of pancreatic fibrosis: Common stromal gene expression in chronic pancreatitis and pancreatic adenocarcinoma. Pancreas 2004; 29: 254-63.

10. Farrow B, Evers BM. Inflammation and the development of pancreatic cancer. Surg Oncoly 2002; 10: 153-69.

11. Bednarz W, Olewinsky R. The influence of chronic pancreatitis on carcinogenesis: An experimental study in rats. Eur J Gastroenterol Hepatology 2002; 14: 671-7. 